\title{
Severity and Outcomes of Afro-Caribbean Patients Diagnosed with Community- Acquired Acute Kidney Injury at an Institution in Jamaica
}

\author{
KK Hoe ${ }^{1}$, EN Barton ${ }^{1}$, AK Soyibo ${ }^{1}$, J Chávez-Iñiguez², G Garcia-Garcia²
}

\begin{abstract}
There is limited data on community-acquired acute kidney injury (CA-AKI) in low/middle-income countries. This retrospective study focussed on the prevalence, severity and outcomes of CA-AKI at an institution in Jamaica. The selected population was patients who attended the University Hospital of the West Indies between January 2015 and June 2015. Acquired kidney injury was diagnosed and staged by KDIGO criteria. Four hundred and thirty-two patients (4.22\%) met the diagnostic criteria of acute kidney injury (AKI). Of these, 171 (39.6\%) had stage I AKI, 110 (25.5\%) had stage II and 151 (35.0\%) had stage III. Certain underlying causes such as volume depletion, various infections and cardiac failure were most prevalent causes of CA-AKI. Among the underlying causes, volume depletion remained as the leading cause of CA-AKI. Patients who had underlying causes which required urgent medical attention are likely to achieve recognition of CA-AKI at an early stage (95\% CI: 1.884, 2.128, $\mathrm{p}<0.001)$. Volume depletion and cardiac failure significantly increased the risk of CA-AKI (OR. 2.037, 95\% CI: 1.130, 1.651, $\mathrm{p}=$ 0.004 and $O R, 1.759,95 \%$ CI: 1.827, 1.982, $\mathrm{p}=0.03)$, respectively. Ninety-four patients (21.8\%) had incomplete and 46 patients (10.6\%) had no renal recovery at $\geq 90$ days. The majority of patients who achieved complete renal recovery were patients who had stage I AKI (90.1\%). Fifty-two patients with CAAKI (12\%) required dialysis and most of them (86.5\%) had stage III AKI. Stages I and II CA-AKI had better renal outcomes than stage III CA-AKI (95\% CI: 1.566, 1.875, $\mathrm{p}<0.001)$. The 30-day mortality and 90-day mortality among the patients with CA-AKI were $6.3 \%$ and $7.4 \%$, respectively.

The severity of CA-AKI varies with underlying cause. Earlier medical attention may link with better renal recovery. Volume depletion and cardiac failure are significant risk factors for CA-AKI and volume depletion remains as the leading cause of CA-AKI.Adverse outcomes are more likely to occur in patients with Stage III CA-AKI.
\end{abstract}

Keywords: Cardiac failure, chronic kidney disease, community-acquired acute kidney injury, pneumonia

\section{Gravedad y Resultados de Pacientes Afrocaribeños Diagnosticados con Lesión Renal Aguda Comunitaria en una Institución en Jamaica}

KK Hoe ${ }^{1}$, EN Barton ${ }^{1}$, AK Soyibo ${ }^{1}$, J Chávez-Iñiguez ${ }^{2}$, G Garcia-Garcia ${ }^{2}$

\begin{abstract}
RESUMEN
Los datos acerca de la lesión renal aguda adquirida en la comunidad (LRA-AC) en países de ingresos bajos y medios, son limitados. Este estudio retrospectivo se centró en la prevalencia, gravedad y resultados de LRA-AC en una institución en Jamaica. La población seleccionada estuvo formada por pacientes que acudieron al Hospital Universitario de West Indies entre enero de 2015 y junio de 2015. La lesión renal adquirida fue diagnosticada y dividida en etapas de acuerdo con los criterios de la organización KDIGO (siglas en inglés de "Enfermedad Renal: Mejorando los Resultados Globales"). Cuatrocientos treinta y dos pacientes (4.22\%) cumplieron los criterios de diagnóstico de LRA. De estos, 171 (39.6\%) estaban en la etapa I de LRA, 110 (25.5\%) en la etapa II, y 151 (35.0\%) en la etapa III. Ciertas causas subyacentes tales como la depleción del volumen, varias infecciones, y la insuficiencia cardíaca fueron las causas más prevalentes de LRA-AC. Entre las causas subyacentes, la depleción del volumen
\end{abstract}

From: ${ }^{1}$ Department of Medicine, Nephrology and Hypertension division, The University of the West Indies, Mona, Jamaica and ${ }^{2}$ Nephrology division, University of the Guadalajara Science and Health Centre, Guadalajara Jelisco, Mexico.
Correspondence: Dr K Hoe, Department of Medicine, The University of the West Indies, Kingston 7. E-mail: kk_hoe@hotmail.com 
permaneció como la principal causa de LRA-AC. Los pacientes con causas subyacentes que requerían atención médica urgente tenían mayor probabilidad de reconocimiento de LRA-AC en una etapa temprana (IC de 95\%: 1.884, 2.128, p < 0.001). La depleción del volumen y la insuficiencia cardiaca aumentaron significativamente el riesgo de LRA-AC (OR. 2.037, IC de 95\%: 1.130, 1.651, p = 0.004 y OR. 1.759, IC de 95\%: 1.827, 1.982, p = 0.03), respectivamente. Noventa y cuatro pacientes (21.8\%) tuvieron una recuperación renal incompleta y 46 pacientes (10.6\%) no tuvieron recuperación ninguna a los $\geq 90$ días. La mayoría de los pacientes que lograron una recuperación renal completa eran pacientes en la etapa I de LRA (90.1\%). Cincuenta y dos pacientes con LRA-AC (12\%) requirieron diálisis y la mayor parte de ellos (86.5\%) se encontraban en la etapa III de LRA. Las etapas I y II de LRA-AC tuvieron mejores re-sultados renales que la etapa III de LRA-AC (IC de 95\%: 1.566, 1.875, $\mathrm{p}<0.001)$. La mortalidad a los 30 días y a los 90 días entre los pacientes con LRA-AC fue de 6.3\% y $7.4 \%$, respectivamente.

La gravedad de la LRA-AC varía según la causa subyacente. La atención médica temprana puede asociarse con una mejor recuperación renal. La depleción del volumen y la insuficiencia cardíaca son factores de riesgo significativos en la LRA-AC, y la depleción del volumen sigue siendo la causa principal de LRA-AC. Los resultados adversos son más probables en pacientes de la etapa III de LRA-AC.

Palabras claves: Enfermedad renal crónica, insuficiencia cardíaca, lesión renal aguda adquirida en la comunidad, neumonía

West Indian Med J 2017; 66 (1): 142

\section{INTRODUCTION}

It would be difficult to control acute kidney injury (AKI) without knowing the actual prevalence and the characteristics of community-acquired acute kidney injury (CA-AKI). Acute kidney injury among hospitalized patients has been the focus of many reports by clinicians. However, AKI which is acquired in the community has not received sufficient attention. Hence, the exact prevalence and incidence of AKI in both developed and developing countries is not known. There are very limited data available for CA-AKI worldwide, especially from the low/middle-income countries.

There is also a disproportionate number of previous studies on CA-AKI and hospital acquired AKI (HA-AKI) resulting in an inconclusive incidence of AKI. The early diagnosis of AKI is the key to therapeutic success. The awareness of limiting AKI risks in the community and its impact on healthcare costs and preventive care was stated in a United States-based study in Kentucky. The study demonstrated that CA-AKI was far more common than HA-AKI and contributed $79.4 \%$ of total AKI (1). A recent United Kingdom (UK) study agreed that $\mathrm{CA}-\mathrm{AKI}$ is more common than HA-AKI and was found more in the younger age group and more severe than HA-AKI. Although CA-AKI patients have similar risk factors to those of patients with HA-AKI, they have better short- and long-term outcomes (2).

At the 2013 World Congress of Nephrology in Hong Kong, the International Society of Nephrology (ISN) set a goal to eliminate preventable and treatable deaths from AKI world-wide by 2025. This plan is now well-known as the 0by25 initiative (Zero preventable deaths from AKI by 2025). Meanwhile, among the 1.7 million estimated global deaths from AKI per year, 82\% (1.4 million) of deaths occur in the low/middle-income countries (3). Although annual incidence of AKI in developing countries is estimated to be 13.3 million cases per year, there are no actual data available from most developing countries. This would be a major obstacle to achieving the ISN goal of the 0by 25.

\section{Defining AKI and its staging}

The kidney disease initiative global outcomes (KDIGO) group set the all-inclusive definition and staging of AKI based on risk, injury, failure, loss, end-stage (RIFLE) and acute kidney injury network (AKIN) criteria. At present, AKI is defined when there is an increase in serum creatinine $(\mathrm{SCr})$ by $0.3 \mathrm{mg} / \mathrm{dL}(26.5 \mu \mathrm{mol} / \mathrm{L})$ within 48 hours; or increase in $\mathrm{SCr}$ to 1.5 times baseline, which is known or presumed to have occurred within the prior seven days; or Urine volume $<$ $0.5 \mathrm{~mL} / \mathrm{kg} / \mathrm{h}$ for six hours (4). However, diagnosis of AKI is difficult when base-line serum creatinine is unknown. It has led to delay in diag-nosis of AKI at first contact for nonoliguric patients whose baseline renal function was unknown. It was estimated that two-thirds of cases with AKI begin prior to admission as CA-AKI and to differentiate AKI from CKD is quite challenging (5). When baseline serum creatinine $(\mathrm{bCr})$ is not known, the $\mathrm{SCr}$ above the reference range should be considered as an acute change until proven otherwise $(6,7)$. In 2009, Hackworth and colleagues issued a serious reminder based on a 20000 -patient database that many previous studies excluded patients whose initial SCr was already elevated. This would mostly affect developing countries where the majority of AKI is thought to be community-acquired (6). With an increasing awareness of that, the recommendation to use the modification of diet in renal disease (MDRD) study equation assuming that baseline eGF R is equivalent to GF R of $75 \mathrm{~mL} / \mathrm{min}$ per $1.73 \mathrm{~m}^{2}$ for a particular age was included in KDIGO guidelines. This approach has been validated and used in many studies to estimate baseline $\operatorname{SCr}(4,8,9)$. The serum creatinine based AKI staging by KDIGO described as stage I when the rise 
of $\mathrm{SCr}$ is $>1.5$ times, stage II when the rise is $>2$ times and stage III when the rise is $>3$ times from the base-line which is known or presumed to have occurred within the prior seven days (4).

\section{SUBJECTS AND METHODS}

A retrospective prevalence study was conducted to identify the cases of community-acquired acute kidney injury (CA-AKI). The chosen patient population was those patients who attended the Accident and Emergency (A\&E) Department of the University Hospital of the West Indies for various acute medical problems from January 2015 to June 2015. Ethical approval for the study was granted by the Ethics Committee of the Faculty of Medical Sciences, The University of the West Indies/University Hospital of the West Indies, Mona, Jamaica.

\section{Patients and procedures}

All patients who had CA-AKI in this study were age 16 years or over and were not on any renal replacement therapy. An equal number of patients to CA-AKI with serum creatinine less than $0.8 \mathrm{mg} / \mathrm{dL}(71 \mu \mathrm{mol} / \mathrm{L})$ or calculated eGFR $>75 \mathrm{~mL} /$ $\mathrm{min} / 1.73 \mathrm{~m}^{2}$ at presentation were randomly selected and included in the non-CA-AKI group for comparison. Demographic, clinical, diagnostic and laboratory variables were extracted by docket review. Demographic variables include: age, gender, ethnicity and country of origin. Laboratory variables such as baseline serum creatinine, serum creatinine at presentation, peak serum creatinine within seven days after presentation and subsequent serum creatinine at 30 days and 90 days were obtained for CA-AKI patients from individual dockets. When the baseline serum creatinine (bSCr) was unknown, the bSCr was estimated by using calculated creatinine-based GFR of $75 \mathrm{~mL} / \mathrm{min} / 1.7 \mathrm{~m}^{2}$ for age as the baseline creatinine for that particular patient. Then, the diagnosis and staging of AKI was verified by applying serum creatinine based KDIGO criteria when SCr rise was $>1.5$ times from baseline which was presumed to occur in the past seven days or when absolute $\mathrm{SCr}$ rise $>0.3 \mathrm{mg} / \mathrm{dL}(26.5 \mu \mathrm{mol} / \mathrm{L})$ in the past 48 hours was ensured. Associated diagnostic variables were obtained from the final assessment at the time of presentation and they were categorized as necessary.

Outcomes of interest were prevalent CA-AKI, the severity of CA-AKI, risk and correlation between underlying causes and CA-AKI, a correlation between severity and outcomes including all-cause mortality.

Defining categories of some underlying causes Volume depletion is considered when extra-cellular fluid (ECF) volume is contracted as a result of a loss of total body sodium. The causes of volume depletion include, vomiting, excessive sweating, diarrhoea, burns and diuretic use (10). In this study, pneumonia indicates community-acquired pneumonia, healthcare-associated pneumonia and hospital acquired pneumonia. Surgical emergency is defined as a medical emergency for which immediate surgical intervention is the only way to solve the problem successfully. Examples of surgical emergency include, pericardial tamponade, acute appendicitis, bowel obstruction, gastrointestinal perforation, intestinal volvulus, acute mesenteric ischaemia, peritonitis, bleeding ectopic pregnancy etc (11). Traumatic injury is a term which refers to physical injuries of sudden onset and severity which require immediate medical attention (12). Mucocutaneous infection involves infection of the skin, mucous membranes and nails.

\section{Statistical analysis}

Continuous numerical variables are expressed as mean $\pm \mathrm{SD}$, and categorical data are expressed as numbers and percentages. The Pearson Chi-square $\left(\mathrm{X}^{2}\right)$ test was used to compare the proportion of different outcomes among different stages of CA-AKI. Both Pearson Chi-square and Phi test were used to compare the correlation, level of association and odd ratio of the most commonly observed underlying causes in patients in CA-AKI group and patients in CA-AKI group. One-way ANOVA test was used for comparing means of numerical data. A $p$-value $<0.05$ was considered statistically significant. The data of correlation between sample populations were applied by means of $95 \%$ confidence interval (CI). All statistical analyses were done by using IBM SPSS version 22 .

\section{RESULTS}

There were 10233 patients who required serum creatinine test done at the A\&E Department of the University Hospital of the West Indies from January to June 2015. Four hundred and thirty-two patients $(4.22 \%)$ were assessed as having CA-AKI based on history, past medical history and measured $\mathrm{SCr}$ results. In these patients with CA-AKI, 220 (50.9\%) were males and $212(49.1 \%)$ were females. The majority of CAAKI patients in this study are Afro-Caribbean (97.7\%).

Mean age \pm SD of patients with CA-AKI was $54.81 \pm$ 16.76 years. Mean peak serum creatinine at presentations were $131 \pm 31(1.48 \pm 0.35), 217 \pm 31(2.45 \pm 0.35)$ and $593 \pm 133$ $(6.7 \pm 1.5) \mu \mathrm{mol} / \mathrm{L}(\mathrm{mg} / \mathrm{dL})$ for stages I, II and II AKI, respectively, and $302 \pm 305(3.41 \pm 3.35) \mu \mathrm{mol} / \mathrm{L}(\mathrm{mg} / \mathrm{dL})$ for overall CA-AKI cases. One hundred and thirteen patients $(26.1 \%)$ had previous serum creatinine test done in the past twelve months. Based on KDIGO staging criteria, 171 patients $(39.6 \%)$ were assessed as stage I, 110 patients (25.5\%) had stage II AKI and 151 patients (34.9\%) had stage III AKI (Table 1).

Certain underlying causes were $\geq 5 \%$ prevalent in CAAKI (Fig. 1). These include volume depletion (10.2\%), pneumonia $(8.8 \%)$, traumatic injury and mucocutaneous infection $(6.5 \%$ each), cardiac failure $(8.6 \%)$, surgical emergency $(6.3 \%)$, acute viral infection $(7.4 \%)$, urinary tract obstruction and urinary tract infection $(5.8 \%$ each). Other clinical conditions which had $1-5 \%$ prevalent rate in CA-AKI in this study were gastrointestinal bleeding (GI) bleeding (3.7\%), urogeni- 
Table 1: Baseline characteristics, severity and outcomes of the patients with community-acquired acute kidney injury n (\%)

\begin{tabular}{|c|c|c|c|c|}
\hline Characteristic (n) & AKI stage I & AKI stage II & AKI stage III & Total CA-AKI \\
\hline \multicolumn{5}{|l|}{ General characteristics } \\
\hline Number of patients (\%) & $171(39.6)$ & $110(25.5)$ & $151(35.0)$ & $432(100)$ \\
\hline $\operatorname{Age}(\mathrm{yrs} \pm \mathrm{sd})$ & $51.7 \pm 17.6$ & $56.7 \pm 17.2$ & $54.7 \pm 15.8$ & $54.9 \pm 16.5(18,99)$ \\
\hline \multicolumn{5}{|l|}{ Gender $\{\mathrm{n}(\%)\}$} \\
\hline Male & $70(16.2)$ & $78(18.1)$ & $72(16.7)$ & $220(50.9)$ \\
\hline Female & $87(20.1)$ & $64(14.8)$ & $61(14.1)$ & $212(49.1)$ \\
\hline $\begin{array}{l}\text { Mean } \mathrm{SCr} \text { at presentation } \\
(\mu \mathrm{mol} / \mathrm{L})\end{array}$ & $131 \pm 31.4$ & $216 \pm 30.7$ & $593 \pm 133$ & $301 \pm 305$ \\
\hline$\geq 1+$ dipstick proteinuria & $26(6)$ & $23(5.3)$ & $56(13.0)$ & $105(24.3)$ \\
\hline \multicolumn{5}{|l|}{ Complete renal recovery } \\
\hline \multicolumn{5}{|l|}{ Renal outcomes at $\geq 90$ days } \\
\hline Back to baseline & $154(90.1)$ & $61(55.5)$ & $64(42.4)$ & $279(69.7)$ \\
\hline Incomplete renal recovery & $9(5.3)$ & $35(31.8)$ & $39(25.8)$ & $83(20.7)$ \\
\hline No recovery & $5(2.9)$ & $8(7.3)$ & $26(17.2)$ & $37(9.6)$ \\
\hline Requirement of dialysis & $3(0.7)$ & $4(0.9)$ & $45(10.4)$ & $52(12.0)$ \\
\hline Requirement of admission & $70(16.2)$ & $79(18.3)$ & $94(21.8)$ & $243(56.3)$ \\
\hline 30-day mortality & $2(0.5)$ & $7(1.6)$ & $18(4.2)$ & $27(6.3)$ \\
\hline 90-day mortality & $3(0.7)$ & $7(1.6)$ & $22(5.1)$ & $32(7.4)$ \\
\hline
\end{tabular}

CA-AKI: community-acquired acute kidney injury, AKI: acute kidney injury

ital malignancy $(3.0 \%)$, acute poisoning $(2.3 \%)$, acute coronary syndrome $(2.1 \%)$, bone fracture $(1.6 \%)$, HIV-infection (1.4\%), systemic lupus erythematosus $(1.4 \%)$ and chronic liver disease $(1.4 \%)$. Sporadic diagnoses which had $<1 \%$ prevalence in CA-AKI were: sickle cell crisis, diabetic emergency, arthritis, acute stroke, rhabdomyolysis, nonurogenital malignancy, deep vein thrombosis, migraine and nephrotic syndrome. The prevalence of malaria and snake bite during our study period was virtually nil. Collectively, underlying infections were prevalent up to $37 \%$ among patients with CA-AKI. The most prevalent underlying causes found in patients with CA-AKI are described in Figure 1.

In Pearson bivariate correlation and linear-by-linear association to correlate these clinical conditions with different AKI stages, we observed that CA-AKI stages I and III were more prevalent than stage II. In addition, data on the distribution of different stages of AKI among the most prevalent underlying diagnoses demonstrated that $4.6 \%, 2.5 \%$ and $3.0 \%$ for stages I, II and III, respectively, were found in patients with volume depletion, stage I (3.7\%), stage II ( $2.3 \%)$ and stage III $(3.0 \%)$ in patients with pneumonia, stage I $(2.5 \%)$, stage II $(3.0 \%)$ and stage III $(3.0 \%)$ among patients with cardiac failure, stage I $(3.0 \%)$, stage II $(2.5 \%)$ and stage III $(1.9 \%)$ in patients with acute viral infection, stage I (3.9\%), stage II (1.2\%) and stage III $(1.4 \%)$ in patients with traumatic injury, stage I (3.0\%), stage II $(2.5 \%)$ and stage III $(0.7 \%)$ in patients with surgical emergency, stage I (1.4\%), stage II (1.2\%) and stage III $(3.2 \%)$ in patients with urinary tract infection, stage I $(1.2 \%)$, stage II $(1.2 \%)$ and stage III $(3.5 \%)$ in patients with urinary tract obstruction, stage I (1.9\%), stage II $(1.2 \%)$ and stage III $(2.5 \%)$ in patients with mucocutaneous infection and stage I $(0.7 \%)$, stage II (1.9\%) and stage III (1.2\%) in patients
Fig 1: Frequency of most prevalent underlying causes in patients with CA-AKI

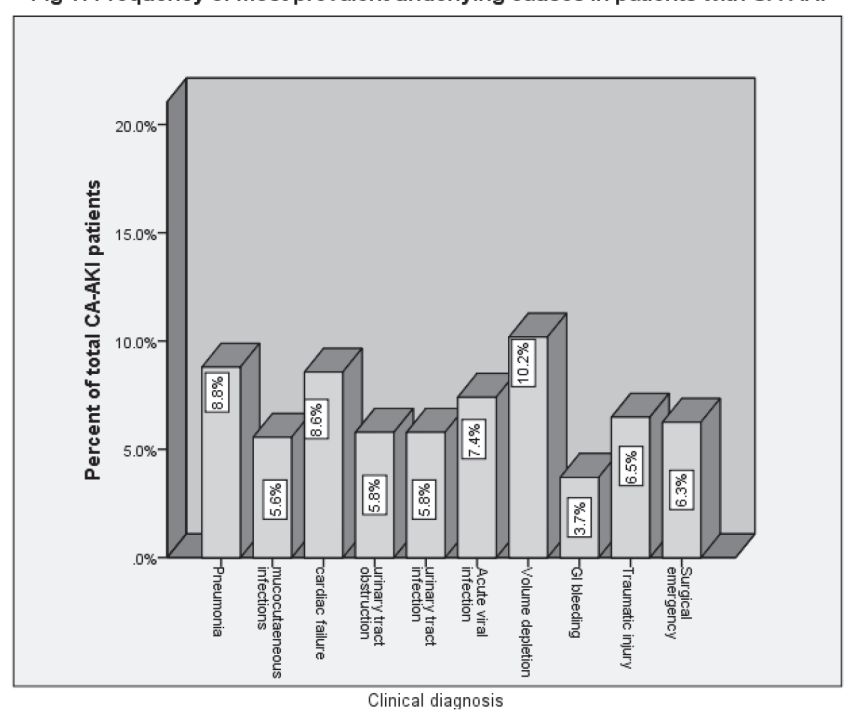

Fig. 1: This figure shows the frequency of most prevalent clinical diagnoses in patients with CA-AKI. Common community based clinical problems which were more prevalent among CA-AKI patients include volume depletion (10.2\%), pneumonia $(8.8 \%)$, cardiac failure $(8.6 \%)$, acute viral infection (7.4\%), traumatic injuries $(6.5 \%)$, acute surgical problems $(6.3 \%)$, urinary tract infection and urinary tract obstruction (5.8\% each), mucocutaneous infection (5.6\%) and gastrointestinal bleeding $(3.7 \%)$. Geographical variation must be considered as no report about other common causes such as malaria and snake bite were observed in this study region.

with gastrointestinal bleeding. In linear regression analysis, urinary tract infection, mucocutaneous infection and urinary tract obstruction were significantly associated with stage III AKI and the number of stage I AKI was significantly higher 
in patients with volume depletion, traumatic injury and surgical emergency (95\% CI: 1.884, 2.128, $p<0.001)$ [Table 2, Fig. 2].

Mean age of patients in the non-CA-AKI group was $47.85 \pm 16.94$ years compared to $54.81 \pm 16.76$ years in the CA-AKI group. Two hundred and twenty males $(50.9 \%)$ and 212 females (49.1\%) were involved in the CA-AKI group. In the randomly selected non-CA-AKI group, 273 (63.2\%) were males and $169(36.8 \%)$ were females. In the categorical analyses of most prevalent underlying causes of CA-AKI, volume depletion had a significantly strong association with CA-AKI (OR, 2.037, 95\% CI: 1.316, 3.412, $p=0.004)$. Cardiac failure was also significantly associated with CA-AKI (OR, 1.759, $95 \%$ CI: $1.045,1.796, p=0.03)$. Pneumonia was the most frequently found infection among the patients with CA-AKI $(8.8 \%)$ but the evidence showed that its correlation to CA-AKI was statistically insignificant and the level of association was also weak (OR, 1.194, 95\% CI: 0.068, 1.374, $p=0.27$ ).

The prevalence of urinary tract infection was significantly higher among patients with non-CA-AKI compared to patients with CA-AKI (OR, 0.546, 95\% CI: 0.511, 0.975, $p=$ $0.01)$. Further correlation analysis between clinical diagnoses and CA-AKI expressed that no significant positive correlation to AKI was observed in patients with traumatic injury (OR,

Table 2: Prevalence of different categories of contributory causes in different stages of community-acquired acute kidney injury [n (\%)]

\begin{tabular}{lcccc}
\hline AKI stages & Stage I [167 (38.7)] & Stage II [114 (26.4)] & Stage III [151 (35.0)] & Overall [432 (100)] \\
\hline Volume depletion & $20(4.6)$ & $11(2.5)$ & $13(3.0)$ & $44(10.2)$ \\
Pneumonia & $16(3.7)$ & $9(2.1)$ & $13(3.0)$ & $38(8.8)$ \\
Traumatic injury & $17(3.9)$ & $5(1.2)$ & $6(1.4)$ & $28(6.5)$ \\
Cardiac failure & $11(2.5)$ & $13(3.0)$ & $13(3.0)$ & $37(8.6)$ \\
Acute surgical conditions & $14(3.2)$ & $10(2.3)$ & $3(0.7)$ & $27(6.4)$ \\
Acute viral illnesses & $13(3.0)$ & $11(2.5)$ & $8(1.9)$ & $32(7.4)$ \\
& & & & \\
Urinary tract infection & $6(1.4)$ & $5(1.2)$ & $14(3.2)$ & $25(5.8)$ \\
Urinary tract obstruction & $5(1.2)$ & $5(1.2)$ & $15(3.5)$ & $25(5.8)$ \\
Mucocutaneous infection & $8(1.9)$ & $5(1.2)$ & $11(2.5)$ & $24(5.5)$ \\
GI bleeding & $3(0.7)$ & $8(1.9)$ & $5(1.2)$ & $16(3.7)$ \\
Others & $58(13.4)$ & $38(6.5)$ & $50(11.6)$ & $136(31.5)$ \\
\hline
\end{tabular}

GI: gastrointestinal bleeding

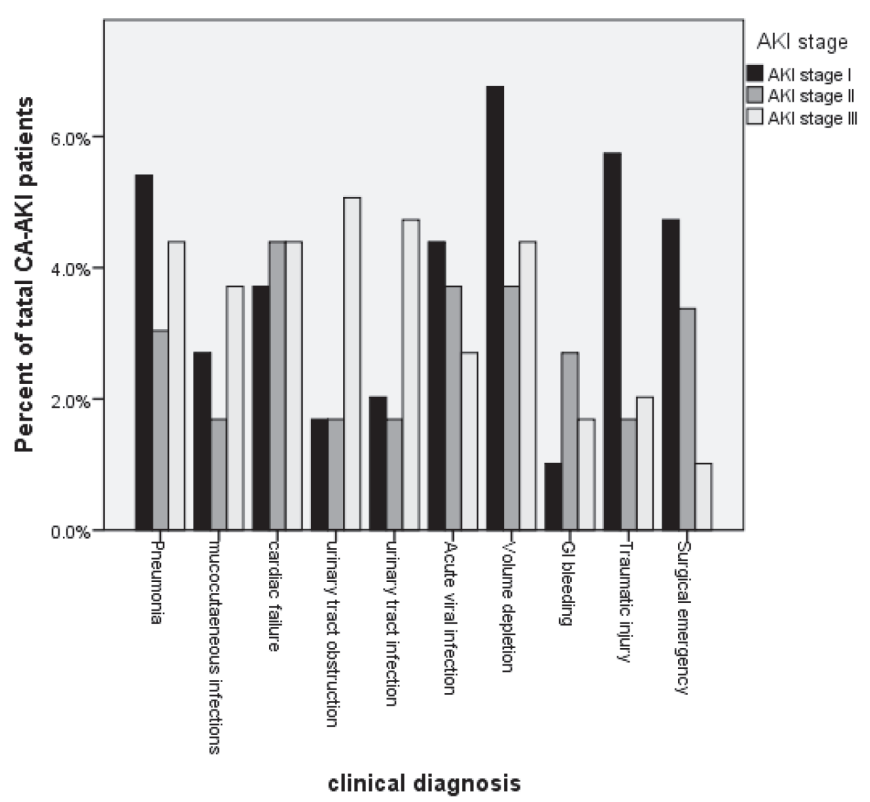

Fig. 2: This figure showed that volume depletion, traumatic injuries and acute surgical conditions were significantly associated with stage I AKI. On the other hand, mucocutaneous infections, urinary tract infection and urinary tract obstruction were significantly higher in stage III AKI.
0.799, 95\% CI: $0.692,1.137, p=0.323)$, surgical emergency (OR, 0.673, 95\% CI: 0.594, 1.085), acute viral infection (OR, $0.678,95 \%$ CI: $0.612,1.065, p=0.10)$, mucocutaneous infections (OR, $0.916,95 \% \mathrm{CI}: 0.722$ to $1.263, p=0.42$ ), urinary tract obstruction (OR, 1.685, 95\% CI: 0.982, 1.635, $p=0.107$ and gastrointestinal bleeding (OR, 0.883, 95\% CI: 0.777 , $1.448, p=0.42)$. The detailed analysis of the correlation between these most commonly observed underlying causes in CA-AKI and non-CA-KI groups is shown in Table 3 and Fig. 3.

The SCr results at day 30 showed that 197 patients (45.6\%) regained baseline renal function, 102 (23.6\%) had some improvement in renal function but not to the baseline and 49 patients $(11.3 \%)$ had no renal recovery. The subsequent follow-up of alive patients at $\geq 90$ days after AKI demonstrated that the vast majority of stage I CA-AKI patients $(90.1 \%, \mathrm{n}=$ 157) regained baseline renal function. Among the patients with stage II CA-AKI, 61 patients $(55.5 \%)$ regained baseline renal function, 35 patients $(31.8 \%)$ had incomplete renal recovery and eight $(7.3 \%)$ had no recovery. The renal outcomes were worst among the stage III group where complete recovery was observed in 64 patients $(42.4 \%)$, incomplete recovery in 39 patients $(25.8 \%)$ and no recovery of renal function in 26 patients (17.2\%). Overall, 197 patients (45.6\%) and 279 patients 
Table 3: Correlation and risk of the most prevalent underlying causes: CA-AKI vs Non-CA-AKI; n (\%)

\begin{tabular}{lccccc}
\hline Parameters & $\begin{array}{c}\text { CA-AKI } \\
(\mathbf{n}=\mathbf{4 3 2})\end{array}$ & $\begin{array}{c}\text { Non-CA-AKI } \\
(\mathbf{n}=\mathbf{4 3 2})\end{array}$ & Odd ratio & 95\% CI & $p$-value \\
\hline Age & $54.81 \pm 16.76$ & $47.85 \pm 16.94$ & & & \\
Gender & & & & & \\
$\quad$ Male & $208(48.1)$ & $236(54.6)$ & & & \\
$\quad$ Female & $224(51.9)$ & $196(45.4)$ & & & \\
Volume depletion & $44(10.2)$ & $24(5.6)$ & 2.037 & $1.316-3.412$ & 0.004 \\
Pneumonia & $38(8.8)$ & $34(7.9)$ & 1.194 & $0.868-1.374$ & 0.275 \\
Cardiac failure & $37(8.6)$ & $23(5.2)$ & 1.759 & $1.045-1.796$ & 0.037 \\
Acute viral infection & $32(7.4)$ & $48(11.1)$ & 0.678 & $0.612-1.065$ & 0.103 \\
Mucocutaneous infection & $28(6.5)$ & $32(7.4)$ & 0.916 & $0.722-1.263$ & 0.424 \\
Traumatic injury & $28(6.5)$ & $39(9.0)$ & 0.799 & $0.692-1.137$ & 0.323 \\
Surgical emergency & $27(6.3)$ & $41(9.5)$ & 0.673 & $0.594-1.085$ & 0.078 \\
Urinary tract infection & $25(5.8)$ & $37(8.6)$ & 0.546 & $0.511-0.975$ & 0.018 \\
Urinary tract obstruction & $25(5.8)$ & $16(3.7)$ & 1.685 & $0.982-1.635$ & 0.107 \\
GI bleeding & $16(3.7)$ & $19(4.4)$ & 0.883 & $0.777-1.448$ & 0.426 \\
Others & $132(30.6)$ & $119(27.5)$ & NA & NA & NA \\
\hline
\end{tabular}

This table showed volume depletion is a significant risk factor for CA-AKI. Similar significant positive correlation to CA-AKI was observed in patients with cardiac failure (ALVF/Decompensated CCF). Cardiac failure $=$ Acute left ventricular failure or decompensated congestive cardiac failure, others $=$ diagnoses not in the list or diagnosis uncertain. GI: gastrointestinal bleeding.

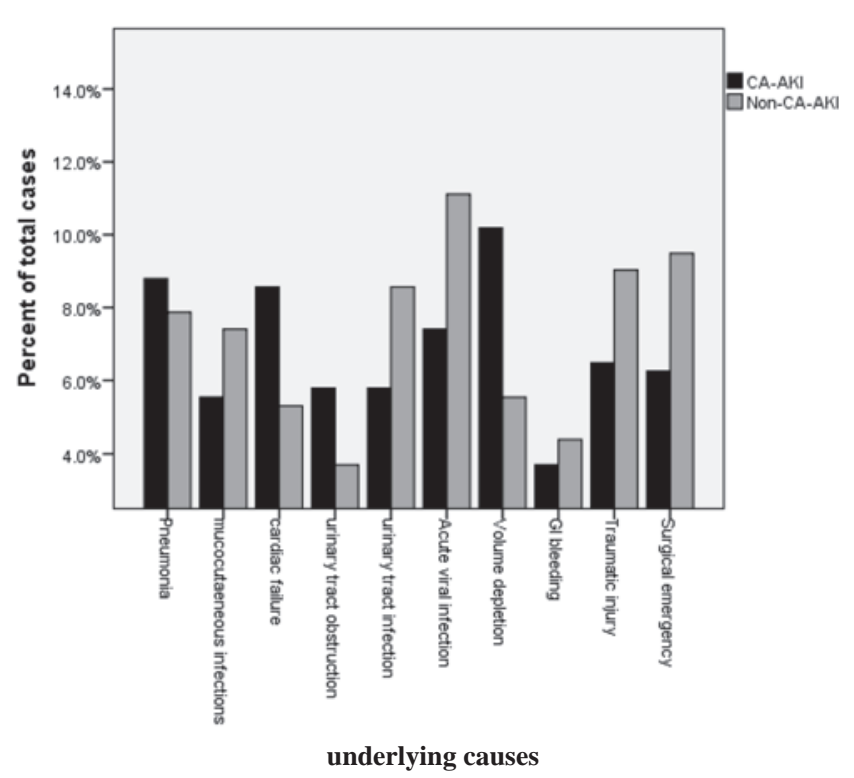

Fig. 3: This figure demonstrated the correlation of underlying causes with CA-AKI and non-CA-AKI group. Compare to non-CA-AKI group, volume depletion, pneumonia, cardiac failure and urinary tract obstruction were more prevalent in patients with CA-AKI.

(69.7\%) regained bSCr at 30 days and 90 days, respectively. Total number of incomplete renal recovery was $83(20.7 \%)$ and no renal recovery was $37(9.6 \%)$. On review of background medical history, 30 patients $(6.9 \%)$ were found to have underlying chronic kidney disease with previously stable baseline renal function. Background chronic kidney disease (CKD) had significant adverse outcomes in AKI as we observed only 11 $(36.7 \%)$ regained their baseline renal function after the acute decline, 14 patients $(46.6 \%)$ showed incomplete renal recovery and five patients (16.7\%) had no improvement in renal function $\geq 90$ days after AKI. After adjustment for mortality and background CKD, conversion of CA-AKI to CKD was $23.4 \%$. Fifty-two patients (12\%) required dialysis, either conventional intermittent haemodialysis or continuous renal replacement therapy and 45 of them $(86.5 \%)$ were assessed as stage III AKI. In comparison, only four patients $(7.7 \%)$ of stage II CAAKI and three patients (5.8\%) of stage I needed dialysis ( $p<$ $0.001,95 \%$ CI:1.52, 1.90). Three hundred and forty-six patients with CA-AKI $(80 \%)$ required hospitalization but no significant difference was observed between different stages of CA-AKI to hospital admission rate $(36.1 \%, 27.8 \%$ and $36.1 \%$ for stages I, II and III, respectively). Mortality at 30-day after CA-AKI was $6.3 \%(\mathrm{n}=27)$ in which stage III contributed most $(66.7 \%, \mathrm{n}=18)$ and to a lesser extent stages II $(25.9 \%, \mathrm{n}=7)$ and $\mathrm{I}(7.4 \%, \mathrm{n}=2)$. At 90 -day after CA-AKI, mortality rate among CA-AKI patients was $7.4 \%(\mathrm{n}=32)$ in which 22 patients $(66.8 \%)$ had stage III, seven patients $(21.9 \%)$ had stage II and three patients $(9.4 \%)$ had stage I. Overall, stage III CAAKI had a high risk of 90-day mortality compared to patients with stages I and II AKI (95\% CI: 1.957, 2.002, $p \leq 0.001)$. Compared to the CA-AKI group, 90-day mortality among selected non-CA-AKI patients was $4.4 \%(\mathrm{n}=19)$ and CA-AKI considerably increased the risk of 90-day mortality (OR= $1.739,95 \% \mathrm{CI}:=0.970,3.118, p=0.06)$.

\section{DISCUSSION}

Community-acquired acute kidney injury is an increasing health concern. In this retrospective study, we found that volume depletion and cardiac failure were significantly associated with CA-AKI. Overall, volume depletion remained as the leading cause of CA-AKI. Infections were highly prevalent in patients with CA-AKI and pneumonia was found to be the 
most prevalent infection. Participants were from Jamaica with a population of $98 \%$ African descent. Thus, the study mainly reflected persons of Afro-Caribbean descent. Previous studies from other regions of the world expressed various precipitating causes of CA-AKI. In fact, the findings of AKI-related studies have changed with the time of the study and geographic area of study. The commonest cause of CA-AKI around the 1990 s was volume depletion $(13,14)$. A few recent publications have expressed that malaria, sepsis, nephrotoxic agents and liver disease are the common causes of AKI nowadays and previously known common causes of AKI such as obstetrical, surgical and diarrhoeal AKI are much less in the current world (15-17). Data from the developed countries demonstrated that sepsis was the leading cause of AKI. Fifty-one per cent of septic shock patients were found to have AKI and their prognosis was worse than those without AKI. Among the causes of sepsis, community-acquired pneumonia was the most common cause of sepsis for hospitalization in these countries $(18,19)$. However, changing the definition and diagnostic criteria of sepsis limited the use of the term "sepsis" and therefore, we avoided the term "sepsis" in this study. In developing countries, despite a significant decline in incidence in diarrhoea-associated AKI in the past three decades, it still remains the leading cause of CA-AKI (15). In this single-centre cohort in Jamaica, we found that volume depletion secondary to vomiting, diarrhoea, burns and diuretic use was the leading cause of CA-AKI.

The KDIGO guideline recommended stratifying the risk of AKI based on individual patient's susceptibility and exposure. We have recognized that individual susceptibility to developing AKI after exposure to the same insult is widely different from person-to-person. Based on multiple studies, the recognised exposures for AKI include sepsis, critical illness, circulatory shock, burns, trauma, cardiac surgery (especially with cardiopulmonary by-pass), major non-cardiac surgery, nephrotoxic drugs, radiocontrast agents and poisonous plants. However, most AKI was found in the susceptible persons which include patients with: dehydration or volume depletion, advanced age, female gender, black race, CKD, chronic diseases (heart, lung, liver), diabetes mellitus, cancer and anaemia (20).

Stewart et al demonstrated that there was delayed recognition of the development of AKI as high as $43 \%$ after admission and one-fifth of these developments were thought to be avoidable. Therefore, during the initial presentation at the $\mathrm{A} \& \mathrm{E}$ Department during an acute illness, the risk assessment for AKI should be done routinely along with serum biochemistry (21).

A study done in the 1990s revealed that the pre-renal cause of AKI was more common in the CA-AKI group when the intrinsic renal injury was a more common finding in the HA-AKI group which carries a higher mortality. The recognised predictors of mortality were oliguria, sepsis, bleeding, the length of ICU stay, the requirement for ventilator and multiorgan failure $(20,22)$. In our cohort, mortality was highest among the stage III CA-AKI group in which complete or partial recovery was significantly less than in patients with stages I and II AKI. Our findings also showed that early or delayed presentation might influence severity. We had more stage III AKI among patients with urinary tract infection, mucocutaneous infection and obstructive uropathy and stage I was more prevalent among patients with volume depletion, traumatic injuries and surgical emergency.

Based on that, we hypothesized that the underlying causes which required urgent medical attention are likely to achieve recognition of CA-AKI at an early stage than other underlying causes which had a relatively slower course of progression. Subsequently, that group with stage I AKI was found to have the best renal outcome. We were able to demonstrate that the vast majority of patients with stage I AKI (90.1\%) regained baseline renal function at $\geq 90$ days in our cohort but the complete renal recovery was significantly less (42.4\%) in patients who had stage III AKI. Severe CA-AKI has a higher risk progressing to CKD. The rate of conversion from CA-AKI to CKD was $23.4 \%$ in this cohort and the majority of them had stage III AKI (79.7\%). Patients with trauma and surgical emergency usually seek medical attention immediately. It might raise the probability of picking up CA-AKI at an early stage among these populations and the importance of early diagnosis and prompt treatment of the underlying cause of the renal outcomes should be well recognized.

Although we did not differentiate mortality based on age, a previous study demonstrated that mortality was higher in younger patients with CA-AKI when HA-AKI caused higher mortality among elderly patients (20). In our cohort, the sample of the CA-AKI population had a mean age of 54.8 years and there was a slight male preponderance $(50.9 \%)$. Previous studies have shown strong evidence of an association between cardiac failure and renal function decline. It was again highlighted in this study $(p=0.03)$. Further studies are necessary to prove whether prevention of cardiac failure may play a significant role in the prevention of CA-AKI $(23,24)$. The majority of patients with background CKD did not regain their baseline renal function after AKI (83.3\%). It strongly reinforced a previously recognized statement that CKD and AKI are independent risk factors for each other with an unfavourable influence on renal outcomes $(8,25)$.

The findings of the worst renal recovery among patients with stage III CA-AKI and the better renal outcomes in patients with stage I CA-AKI were observed at $\geq 90$ days after the onset of AKI. However, the long-term outcome of different stages of CA-AKI remained unanswered in this study and it will be an area for further studies. In a recent cohort done in the UK, researchers demonstrated a significantly high percentage of CA-AKI (71\%) which progressed to CKD in three years of follow-up most likely due to incomplete or no recovery from initial kidney injury. Interestingly, only $54 \%$ of CAAKI patients were admitted and that group achieved better complete renal recovery compared to the non-admitted CAAKI population and overall mortality at three-months after 
AKI was $16.5 \%$ (26). In our cohort, the admission rate among CA-AKI patients was $79.9 \%$ and overall mortality rate at threemonths after CA-AKI was 7.4\%. A comparison study between CA-AKI and HA-AKI cautioned not to underestimate CA-AKI as the finding showed the severity and impact of CA-AKI was not less than that of HA-AKI. These authors also encouraged the prevention of the risks of CA-AKI which undoubtedly would play an important role in the reduction of AKI-related healthcare cost (27). A study published in 1991 pointed out that $90 \%$ of CA-AK (formerly stated as community-acquired acute renal failure) diagnosed on admission had reversible underlying aetiologies of either volume contraction or urinary tract obstruction (28). Based on our findings, reversibility depends highly on the severity and severity was associated with the underlying cause of AKI. Prompt resuscitation of volume depletion, prevention of cardiac failure, pneumonia and viral infections may have some influence to lower the prevalence of CA-AKI. A paper published in June 2016, based on a nationwide cohort, over 10069 pneumococcal pneumonia patients and 10069 non-pneumococcal patients in Taiwan demonstrated that the patients with pneumococcal pneumonia had an increased risk of AKI compared with those without pneumococcal pneumonia after adjustment for age, gender and co-morbidities and the highest risk of AKI was found among elderly male patients over 65 years in the pneumococcal pneumonia group (29). In our study, pneumonia was the most prevalent infection in CA-AKI patients but there was no significant difference found between CA-AKI and non-CA-AKI patients (OR, 1.194, 95\% CI: 0.868, $1.374 p=0.27$ ). Larger studies are necessary to find out the correlation between community-acquired infections and CA-AKI. Another valuable information from the current study would be to focus on early diagnosis of CA-AKI prior to stage III and to treat the underlying cause promptly at stage I CA-AKI which may have a great influence on recent and long-term renal outcomes. Community-acquired acute kidney injury should no longer be a neglected portion of AKI.

\section{Limitations}

This is an observational study in an academic institution. Although we included all available patients who presented and adjusted patient characteristics measured, it does not reflect the entire population of the region particularly the population residing in rural regions where healthcare facilities are very limited. It is highly possible that negative renal outcomes and mortality may be much higher in these areas where no nephrology and dialysis facilities are available. The geographical variation in the underlying causes of acute kidney injury might have influenced the statistical significance of CA-AKI in this study as some recognized common clinical problems in some other parts of the world, such as malaria and snake bites, are extremely rare in the Caribbean.

In addition, we did not address the outcomes of coexisting clinical conditions and effect of successful treatment to the precipitating causes of AKI. The long-term outcomes of CA-
AKI in this study were unknown. A few previous studies differentiated AKI as pre-renal, renal or post-renal AKI. In this study, these diagnostic criteria to differentiate pre-renal and intrinsic renal injury were not applied. We demonstrated the significantly higher need of renal replacement therapy in stage III CA-AKI than stages I or II. In real practice, there have been no specific guidelines stating when to start dialysis in these patients.

Arbitrarily, we consider renal replacement therapy for patients with AKI when $\mathrm{SCr}$ was thought to be significantly high enough to be symptomatic or when we observed anuria or oliguria for an extended period. This might have resulted in some unfavourable outcomes of stage III AKI in our study. In addition, the time of peak SCr which we counted from the time of presentation may have the bias of an estimator. Unlike Hospital acquired AKI, which has a normal renal function on admission by its definition (15), it is quite difficult to predict the actual time of onset and the duration of CA-AKI in real practice because the kidney injury may or may not be accompanied by the onset of the symptoms at presentation. Perhaps, it will remain as a major limitation to stage CA-AKI appropriately in CA-AKI related studies until we have a better community-based AKI definition and staging system.

\section{REFERENCES}

1. Schissler MM, Zaidi S, Kumar H, Deo D, Brier ME, McLeish KR. Characteristics and outcomes in community-acquired versus hospital-acquired acute kidney injury. Nephrology 2013; 18: 183-7.

2. Wonnacot A, Meran S, Amphlett B, Talabani B, Phillips A. Epidemiology and outcomes in community-acquired versus hospital-acquired AKI. Clin J Am Soc Nephrol 2014; 9: 1007-14.

3. ISN 0by25 AKI Initiative. (2016, April 13). Retrieved from www. 0by25.org/

4. KDIGO Clinical Practice Guideline for Acute Kidney Injury. (2012, Jul 2). Retrieved from www.kdigo.org/clinical...guidelines/.../KDIGO $\%$ 20AKI\%20Guideline.pd.

5. Lassnigg A, Schmidlin D, Mouhieddine M, Bachmann LM, Drumi W, Bauer P et al. Minimal changes of serum creatinine predict prognosis in patients after cardiothoracic surgery: a prospective cohort study. J Am Soc Nephrol 2004; 15: 1597-605.

6. Hackworth LA, Wen X, Clermont G. Hospital versus community acquired acute kidney injury in the critically ill: differences in epidemiology (abstr). J Am Soc Nephrol 2009; 20: 115A.

7. Hilton R. Clinical review: acute renal failure. BMJ 2006; 333: 786.

8. Zavada J, Hoste E, Cartin-Ceba R, Caizavacca P, Gajic O, Clemont G et al. A comparison of three methods to estimate baseline creatinine for RIFLE classification. Nephrol Dial Transplant 2010; 25: 3911-8.

9. Siew ED, Matheny ME, Ikizler TA, Lewis JB, Miller RA, Waitman LR et al. Commonly used surrogates for baseline renal function can impact acute kidney injury classification and prognosis. Kidney Int 2010; 77: $536-42$.

10. Lewis JL. Volume Depletion - Endocrine and Metabolic Disorders, Merck Manuals (2014 August). Retreived from www.merckmanuals.com

11. Monson JRT, Duthie G, O’Malley K (Eds.). Surgical Emergencies. Blackwell Science (UK), 1999. Retrieved from http://www.ourmed.org/ wiki/Surgical_emergency

12. Brakenridge $\overline{\mathrm{S}}$, Smith $\mathrm{R}$, Tindall J, Walker J. Traumatic Injury, University of Florida Health. Retrieved from https://ufhealth.org/traumatic-injury

13. Hsu C-y, McCulloch CE, Fan D, Ordoñez JD, Chertow GM, Go AS. Community-based incidence of acute renal failure. Kidney Int 2007; 72: 208-12. 
14. Kaufman J, Dhakal M, Patel B, Hamburger R. Communityacquired acute renal failure. Am J Kidney Dis 1991; 17: 191-8.

15. Prakash J, Singh B, Ghosh B, Malhotra V, Rathore SS, Vohra R et al. Changing epidemiology of community-acquired acute kidney injury in developing countries: analysis of 2405 cases in 26 years from eastern India. Clin Kidney J 2013; 6: 150-5.

16. Lameire N, Biesen WV, Vanholder R. The changing epidemiology of acute renal failure. Nat Clin Pract Nephrol 2006; 2: 364-77.

17. Bellomo R, Ronco C, Kellum JA, Mehta RL, Palevsky P. Acute Dialysis Quality Initiative workgroup. Acute renal failure - definition, outcome measures, animal models, fluid therapy and information technology needs: the Second International Consensus Conference of the Acute Dialysis Quality Initiative (ADQI) Group. Crit Care 2004; 8: R204-12.

18. Murugan R, Karajala-Subramanyam V, Lee M, Yende S, Kong L, Carter $\mathrm{M}$ et al. Genetic and inflammatory markers of sepsis (GenIMS) investigators: acute kidney injury in non-severe pneumonia is associated with an increased immune response and lower survival. Kidney Int 2010; 77: 527-35.

19. Schrier RW, Wang W. Acute renal failure and sepsis. N Engl J Med 2004; 351: $159-69$.

20. Obialo CL, Okanofua EC, Tayade AS, Riley LJ. Epidemiology of de novo acute renal failure in hospitalized African Americans: comparing community-acquired versus hospital-acquired disease. Arch Intern Med 2000; 160: 1309-13.

21. Stewart J, Findlay G, Smith N, Kelly K, Mason M. Adding Insult to Injury: A review of the care of patients who died in hospital with a primary diagnosis of acute kidney injury (acute renal failure). National Confidential Enquiry into Patient Outcome and Death: London, UK, 2009
22. Kohli HS, Bhat A, Jairam A, Aravindan AN, Sud K, Jha V et al. Predictors of mortality in acute renal failure in a developing country: a prospective study. Ren Fail 2007; 29: 463-9.

23. Adams KF Jr, Fonarow GC, Emerman CL, LeJemtel TH, Costanzo MR, Abraham WT et al. Characteristics and outcomes of patients hospitalized for heart failure in the United States: rationale, design, and preliminary observations from the first 100,000 cases in the Acute Decompensated Heart Failure National Registry (ADHERE). Am Heart J 2005; 149: 209-6.

24. McAlister FA, Ezekowtiz J, Tonelli M, Armstrong PW. Renal insufficiency and heart failure: gprognostic and therapeutic implications from a prospective cohort study. Circulation 2003; 109: 1004-9.

25. Hsu CY, Ordoñez JD, Chertow GM, Fan D, McCulloch CE, Go AS. The risk of acute renal failure in patients with chronic kidney disease. Kidney Int 2008; 74: 101- 7 .

26. Talabani B, Zouwail S, Pyart RD, Meran S, Riley SG, Phillips AO. Epi-demiology and outcome of community-acquired acute kidney injury. Neph (Carlton) 2014; 19: 282-7.

27. Schissler MM1, Zaidi S, Kumar H, Deo D, Brier ME, McLeish KR. Characteristics and outcomes in community-acquired versus hospital-acquired acute kidney injury. Nephrology 2013; 18: 183-7.

28. Kaufman J, Dhakal M, Patel B Hamburger R. Community-acquired acute renal failure. Am J Kidney Dis 1991; 17: 191-8.

29. Te-Yu L, Yu-Guang C, Cheng-Li L, Chia-Hung K. Increased risk of acute kidney injury following pneumococcal pneumonia: a nationwide cohort study. PLoS One 2016; 11: e0158501. 